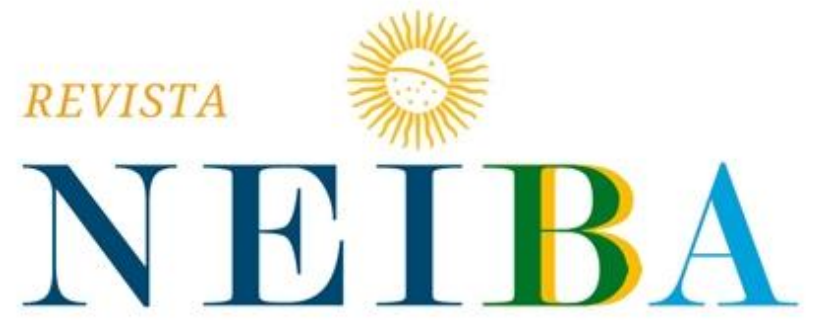

CADERNOS ARGENTINA-BRASIL
Volume 9, 2020, p. 01-21

DOI: 10.12957/neiba.2020.50556 I e50556 I ISSN: 2317-3459

\title{
NORMAS, ISOMORFISMO INSTITUCIONAL E DEMANDA MILITAR: O PROJETO DO SUBMARINO NUCLEAR DA MARINHA DO BRASIL
}

NORMS, INSTITUTIONAL ISOMORPHISM, AND MILITARY PROCUREMENT: THE BRAZILIAN NAVY NUCLEAR SUBMARINE PROJECT

Jonathan de Araújo de Assis ${ }^{1}$

${ }^{1}$ Programa de Pós-Graduação em Relações Internacionais San Tiago Dantas (UNESP, UNICAMP, PUC-SP), São Paulo, SP, Brasil. E-mail: jonathan.assis@unesp.com. ORCID: https://orcid.org/0000-0003-3392-8801.

Recebido em: 01/01/2020 | Aceito em: 27/04/2020. 


\section{RESUMO}

Um extenso corpo da literatura sobre transferência e aquisição de armamentos dedicou-se a analisar os diversos elementos, endógenos e exógenos, que orientam a demanda dos Estados por tecnologia militar. À luz dessas considerações teóricas, diferentes trabalhos buscaram compreender o fenômeno de modernização militar em países da América do Sul e suas potenciais implicações para a dinâmica de segurança regional. Buscamos avançar o argumento de que a demanda por sistemas de armas modernos está vinculada a um processo internacional de isomorfismo das organizações militares. Nesse sentido, nosso objetivo é compreender a demanda da Marinha brasileira pelo submarino de propulsão nuclear. A partir da perspectiva do neoinstitucionalismo sociológico, nossa hipótese é que a demanda da força naval brasileira foi historicamente conformada pela difusão de normas constitutivas sobre o que representa o poder militar moderno.

Palavras-chave: Tecnologia militar; submarino nuclear; Marinha do Brasil.

\section{ABSTRACT}

An extensive literature on arms transfer and acquisition analyzed different elements, endogenous and exogenous, that drive States' demand for military technology. In accordance with these theoretical considerations, different studies sought to understand the phenomenon of military modernizations in South American countries and its potential implications for regional security dynamics. We sought to advance the argument that military demand for modern weapon systems is linked to an international process of isomorphism in military organizations. In that sense, our objective is to comprehend the Brazilian navy demand for a nuclear-powered submarine. In line with the sociological neo-institutionalism framework, we hypothesize that the Brazilian naval force demand has been historically shaped by the diffusion of constitutive norms concerning what constitutes a modern military power.

Keywords: Military technology; nuclear submarine; Brazilian Navy. 


\section{INTRODUÇÃO}

A despeito do quadro de relativa estabilidade política e ausência de conflitos desde o término da Guerra Fria, a primeira década do século XXI foi um período marcado pelo aumento no volume de transferências de armamentos realizadas pelos países sulamericanos. Como dedicam-se a analisar Bromley e Guevara (2010), o volume de armamentos transferidos a países da América Latina cresceu 43\% durante o período de 2003 a 2007 em comparação com o período de 1998 a 2002. Observados apenas os países da América do Sul, o percentual de crescimento entre os períodos em tela é equivalente. Entretanto, quando observada a série histórica de 2001 a 2017, nota-se que as aquisições de armamentos por países sul-americanos apresentaram um substantivo crescimento entre 2005 e 2007 (SIPRI, 2019).

À luz desses dados, Malamud e Encina (2006) argumentam que a existência de uma corrida armamentista na região, encabeçada pela Venezuela, não foi mero discurso. Em contraposição à essa leitura, Villa (2008, p. 48) conclui que as aquisições de armamentos empreendidas por países sul-americanos não indicam uma corrida armamentista nos termos clássicos, mas sim um build-up assentado sobre motivações distintas. A esse respeito, Battaglino (2008) reflete sobre a validade teórica e empírica do conceito de corrida armamentista para o contexto sul-americano.

Em consonância com essas análises, Villa e Weiffen (2014, p. 154) problematizam o alcance explicativo de análises centradas em elementos como ameaças externas e fatores político-econômicos. Nesses termos, sem preterir tais elementos para o contexto sul-americano, indicam um conjunto de motivadores de ordem externa nãoconflitiva que incidem sobre os processos de modernização das forças armadas. Assim, os armamentos também simbolizam a ascensão de uma liderança regional e nutrem sua inserção política nos níveis regional e global (Villa; Weiffen, 2014, p. 155-156).

A partir dessas considerações, buscamos com o presente estudo lançar luz sobre os fatores que levaram à demanda da Marinha brasileira por um submarino de propulsão nuclear. Nossa hipótese é que a demanda da força naval brasileira foi historicamente conformada pela difusão de normas constitutivas sobre o poder militar moderno. Além desta introdução e das considerações finais, o trabalho é composto por três seções. 
$\mathrm{Na}$ primeira seção, introduzimos os principais fundamentos do neoinstitucionalismo sociológico, abordagem teórica que orienta os esforços analíticos deste trabalho. Na segunda seção, apresentamos o desenvolvimento histórico da Marinha brasileira, destacando o papel dos armamentos e da influência estrangeiras sobre a concepção estratégica da força. Na terceira seção, analisamos o projeto de desenvolvimento do submarino de propulsão nuclear e sua relação com os documentos estratégicos brasileiros publicados em meados dos anos 2000.

\section{O NEOINSTITUCIONALISMO SOCIOLÓGICO E A DEMANDA POR ARMAMENTOS}

Antes de avançarmos sobre a análise do programa do submarino nuclear brasileiro, cabe apresentar e discutir alguns dos principais pressupostos e conceitos que fundamentam o que se convencionou chamar de "neoinstitucionalismo sociológico". Diferentemente de outras abordagens, o neoinstitucionalismo sociológico compreende as organizações sob a perspectiva de sistemas abertos, segundo a qual as organizações são profundamente marcadas por uma relação de constituição mútua com o ambiente no qual estão inseridas.

Na obra seminal e amplamente referenciada de Dimaggio e Powell (1983), os autores têm por objetivo compreender os fatores que explicam a homogeneidade de formas e práticas organizacionais. Nesses termos, ao contrário das perspectivas que enfatizam a racionalidade competitiva e a busca por maior eficiência, argumentam que a homogeneização das organizações emerge do processo de estruturação de campos organizacionais. Importante elemento para a compreensão proposta pela abordagem neoinstitucionalista, os autores definem campo organizacional como

[...] aquelas organizações que, no conjunto, constituem uma área
reconhecida da vida institucional: fornecedores chave, recursos e
consumidores, agências reguladoras, e outras organizações que produzem
serviços e produtos similares. (Dimaggio; Powell, 1983, p. 148, tradução
nossa).

Em seus primeiros estágios, um campo organizacional pode apresentar considerável diversidade de formas e práticas; entretanto, uma vez desenvolvido e bem estabelecido, tende a um caminho de homogeneização. Esse processo é bem sumarizado pelo conceito de isomorfismo, que, para os autores, pode se manifestar de duas formas: competitivo e institucional. Sob a primeira forma, o isomorfismo é 
resultado de um sistema de competitividade racional que visa garantir maior eficiência para o cumprimento dos objetivos de uma organização. Em complemento a essa leitura, Dimaggio e Powell (1983, p. 150) propõem uma concepção de isomorfismo que também compreenda pressões de natureza institucional; ou seja, para além da disputa por recursos e consumidores, as organizações também buscam poder político e legitimidade institucional.

De acordo com a tipologia formulada pelos autores, um dos mecanismos por meio do qual ocorre o isomorfismo institucional é a pressão normativa associada à profissionalização. Além de favorecer a criação de redes profissionais que perpassam diferentes organizações, o processo de profissionalização tende a gerar, por meio de normas regulativas e constitutivas compartilhadas, maior convergência entre essas organizações. Segundo os autores,

\begin{abstract}
a troca de informação entre os profissionais contribui para uma hierarquia comumente reconhecida de status, de centro e periferia, que se torna uma matriz para o fluxo de informação e mobilidade de pessoal entre organizações [...] Essas organizações centrais servem tanto como modelo ativo quanto passivo; suas políticas e estruturas serão copiadas por todo o campo. (Dimaggio; Powell, 1983, p. 153).
\end{abstract}

Nesses termos, conforme as organizações alinham-se às prescrições derivadas desses fluxos, o isomorfismo institucional ocorre no interior de um campo organizacional. Conforme destaca Farrell (2005, p. 32), ainda que a abordagem neoinstitucionalista tenha sido empregada em estudos sobre isomorfismo em diversos campos de atividade estatal - tais como educação, bem-estar social e proteção ambiental -, pouco foi produzido sobre o isomorfismo no âmbito da violência organizada do Estado. Uma importante exceção é a obra de Eyre e Suchman (1996), cujos autores produziram um trabalho seminal sobre o isomorfismo internacional das organizações militares. Sem desprezar o argumento de que a aquisição de armamentos também cumpre fundamentos de ordem estratégica e funcional, os autores lançam luz sobre os fatores de natureza ideacional que orientam tais práticas.

A partir dessa perspectiva, tanto as organizações militares quanto os armamentos podem ser imaginados como "[...] servindo funções similares àquelas das bandeiras, linhas aéreas e equipes olímpicas: são parte do que os Estados modernos creem ser preciso possuir para ser um Estado moderno legítimo." (Sagan, 1996, p. 74, tradução 
nossa). Nesse sentido, os armamentos possuem um tipo de valor que extrapola as concepções tradicionais de uso e troca. Isto é, como argumentam Eyre e Suchman (1996, p. 80), além de variarem em termos de incorporação de tecnologias, os armamentos variam em termos de integração institucional ou "peso simbólico".

Em consonância com o debate proposto, Wendt e Barnett (1993) buscam compreender os motivos da predominância de um tipo de militarização em países não desenvolvidos; para tanto, propõem uma distinção tipológica entre os tipos de militarização ${ }^{2}$ : capital-intensivo e trabalho-intensivo. Como apontam os autores, é da militarização de capital-intensivo que derivam os típicos exércitos modernos, os quais embasam suas capacidades sobre capital físico e humano associados a sistemas de armas sofisticados em termos tecnológicos.

Em contrapartida, a militarização do tipo de trabalho-intensivo assenta sua capacidade fundamental sobre a mobilização de massas, que podem se organizar em torno de um núcleo de profissionais e armamentos vinculados ao tipo de capitalintensivo ou de maneira descentralizada, em formatos de guerrilha (Wendt; Barnett, 1993, p. 325-326). Mais do que simples instrumento de análise, a tipologia proposta pelos autores tem uma repercussão política importante de desnaturalizar a militarização de capital-intensivo como processo inevitável. Nesse sentido, e à luz da perspectiva neoinstitucionalista, não é o modelo mais eficiente do ponto de vista estratégico que necessariamente será emulado, mas sim aquele mais acessível, familiar e prestigiado em um campo social (Goldman, 2002, p. 44).

Dessa forma, o sistema de armas também representa uma forma de legitimação e inserção internacional. Como argumenta Kinsella (2013, p. 108), a manutenção de forças armadas modernas e bem equipadas é, em parte, produto da crença de que representam o emblema do Estado moderno na era contemporânea. Tais considerações nos levam a questões distintas daquelas que debatem a formação de preferências dos Estados com base na percepção de ameaças - próprias das abordagens racionalistas -, nos fazendo refletir sobre a constituição das preferências das organizações militares.

\footnotetext{
${ }^{2}$ Com base no trabalho de Ross (1987), os autores compreendem a militarização como um processo de acumulação de capacidades para a violência organizada.
} 


\section{TECNOLOGIA E O DESENVOLVIMENTO DA MARINHA BRASILEIRA}

Em seu estudo sobre o papel da tecnologia no poder naval, Martins Filho (2010a) propõe três conjunturas para compreender o processo de desenvolvimento da Marinha brasileira. Entende que, ao contrário das marinhas de países industrializados, as marinhas de países periféricos desenvolveram-se sob processos de "saltos tecnológicos". À luz dessas considerações, o autor compreende as seguintes conjunturas para o caso brasileiro:

1) a dos programas navais de 1904-1906, que resultaram na aquisição dos encouraçados (dreadnoughts) Minas Geraes e São Paulo; 2) a da Segunda Guerra Mundial, no âmbito dos acordos de lend-lease com os EUA, quando foram incorporados os contratorpedeiros de escolta classe Cannon; 3) a do início dos anos setenta, quando o país adquiriu na Inglaterra as fragatas Vosper MK-10. (Martins Filho, 2010a, p. 58).

Entre meados do século XIX e início do século XX, a construção naval incorporou diferentes inovações tecnológicas que transformaram rapidamente os navios de guerra. Além da adoção do motor à vapor, o período também compreendeu o uso do ferro na construção dos navios, a fim de garantir maior resistência frente aos armamentos que também apresentavam transformações. Como aponta Martins Filho (2010b, p. 13), sob a lógica de oposição entre a capacidade dos armamentos e a resistência dos navios foi que, no final da década de 1850, o canhão embutido passou a ser produzido e, na década de 1880, o aço substituiu o ferro na construção naval.

Além de seus efeitos diretos sobre o desenho e a eficiência dos navios, esse conjunto de inovações também levou a consequências fiscais e políticas. Essas transformações incorporadas aos navios de guerra elevaram de maneira considerável os custos de modernização das marinhas, afetando tanto as grandes quanto as pequenas potências. Em suma,

essa evolução punha fim à possiblidade de países não-industrializados poderem construir Marinha moderna. [...] Com isso, o Brasil, que não se industrializou, perdeu sua condição de construtor naval significativo e passou a depender da importação de suas unidades de guerra. (Vidigal, 1985, p. 112).

A análise dos dois programas navais apresentados no início do século XX nos permite compreender os efeitos dessas circunstâncias sobre os esforços de 
modernização da Marinha brasileira. A primeira das condições necessárias para a elaboração de um plano de reforma naval surgiu no final de 1902, com o "Manifesto inaugural" do recém-eleito presidente Rodrigues Alves (1902-1906). Em seu anúncio, indicou que pretendia dedicar "[...] especial atenção aos interesses das classes armadas, de terra e mar, procurando acudir às suas mais urgentes necessidades e promovendo os melhoramentos que forem compatíveis com os nossos recursos" (Brasil, 1902, p. 910 apud Arias Neto, 2014, p. 98).

Sob esse quadro, o Programa Naval foi apresentado e aprovado pelo Congresso em 1904. O contrato de fabricação dos três encouraçados previstos foi assinado apenas em 1906, após análise das propostas apresentadas pelos estaleiros que resultou na escolha da britânica Armstrong. Entretanto, com o fim do mandato de Rodrigues Alves e início do governo Afonso Pena (1906-1909), mudanças no ministério da Marinha e debates no âmbito do Congresso, levaram a críticas e alterações no plano apresentado em 1904.

Logo após a posse do novo presidente, o Congresso autorizou que fossem realizadas modificações consideradas necessárias no contrato estabelecido com a britânica Armstrong. Nesses termos, inspirada no recém-lançado Dreadnought - navio britânico precursor da era dos grandes encouraçados e armamentos padronizados e de grande calibre -, "a esquadra brasileira passaria, assim, a se constituir basicamente de três dreadnoughts, cada um com deslocamento de 19.280 toneladas e doze canhões de doze polegadas, colocadas aos pares de seis torres" (Martins Filho, 2010a, p. 64).

A chegada dos modernos encouraçados, entretanto, evidenciou a falta de preparo do pessoal para o emprego e manutenção desses navios. Frente a esse contexto, o país contratou, em 1914, oficiais estadunidenses para lecionarem na recém criada Escola Naval de Guerra; posteriormente, em 1922, teve início a Missão Naval Americana, que marcou o princípio de um relacionamento mais estreito entre as marinhas dos dois países. Para Vidigal (1985, p. 75), uma das razões para a contratação da Missão foi a necessidade de preparar adequadamente o pessoal - entre oficiais e subalternos - que iria guarnecer os navios que chegaram em 1910.

O início da Segunda Guerra Mundial intensificou os laços da Marinha brasileira com sua equivalente estadunidense, sobretudo em termos de treinamento e fornecimento 
de armamentos. Sob pressões norte-americanas, o então chanceler Oswaldo Aranha anuncia o rompimento das relações diplomáticas com os países do Eixo, em 1942. Segundo Alves (2005, p. 9), a postura do governo brasileiro foi logo recompensada por créditos suplementares à exploração e produção de matérias primas, além da concessão de um fundo de US\$200 milhões para a aquisição de armamentos por meio de lend-lease.

Em 1942, Brasil e EUA firmaram uma aliança militar formal, que teve como resultado a criação de duas comissões militares binacionais: uma em Washington Comissão Mista de Defesa Brasil-Estados Unidos -, e outra no Rio de Janeiro - Comissão Militar Mista Brasil-Estados Unidos. Além de decidir sobre transferências de equipamentos por meio de lend-lease, a comissão sediada em Washington também tinha a função de estudo e preparo de recomendações referentes à defesa conjunta dos países, ao passo que à comissão situada no Rio de Janeiro cabia auxiliar na implementação de tais recomendações (Alves, 2005, p. 10).

No entanto, a participação da Marinha brasileira na guerra evidenciou sua falta de preparo - doutrinário e material - para a guerra antissubmarina. Frente a incapacidade da força naval em lidar com esse tipo de ameaça, a solução parecia ser justamente a aliança com os EUA (Alves, 2006, p. 11). Nesses termos, foi sob o comando americano que

\footnotetext{
aprendemos a fazer a guerra no mar em moldes modernos, entramos em contato com equipamentos de projeto recente e sofisticados, como o sonar e o radar, passamos a pensar em termos mundiais mais do que em termos regionais, despertamos, mais uma vez, para nossa vocação atlântica. Contudo, à total dependência material somaríamos uma subordinação intelectual esterilizadora nos anos subsequentes. (Vidigal, 1985, p. 89, grifo nosso).
}

Com o término do conflito, o país continuou a receber, a preços simbólicos, material excedente da guerra, ainda que tenha perdido a condição de aliado privilegiado dos norte-americanos. Segundo Svartman (2011, p. 80), apesar de estreita, a aproximação militar entre os países não atendeu parte das expectativas da liderança militar brasileira, particularmente em relação ao desenvolvimento de uma indústria de defesa e no objetivo de alcançar supremacia militar regional. Do ponto de vista da política externa dos EUA, a assinatura do Acordo Militar de 1952 estava inserida no 
escopo mais amplo do Programa de Assistência Militar (PAM), que tinha por finalidade garantir a consecução dos interesses estadunidenses em nível global.

Nesse sentido, o PAM insere-se no contexto da América Latina como instrumento para estreitar os laços militares e de segurança hemisférica, além de fortalecer a influência estadunidense na região, particularmente pelo controle no fornecimento de armamentos e treinamento das forças armadas latino-americanas (Brigagão, 1984, p. 75-76). No que se refere ao poder naval, a assinatura do Acordo não alterou a política de equilíbrio entre os países do Cone Sul na transferência de armamentos praticada pelo governo estadunidense.

Como argumenta Alves (2005, p. 22), os custos inviabilizavam um distanciamento absoluto dos EUA, ao passo que a influência doutrinária e tática refletia a subordinação da Marinha brasileira à estratégia naval estadunidense. A despeito dessa conjuntura, houve esforços no sentindo de diversificar os fornecedores de armamentos, ainda que a concepção estratégica antissubmarina permanecesse inalterada. Como argumenta Vidigal (1985, p. 93), “até o governo Geisel, nossa concepção estratégica, em todos os níveis de expressão, ficou rigorosamente subordinada a essa visão política estadunidense, desestimulando, totalmente, qualquer pensamento original nesse terreno".

Entretanto, já no período final da década de 1960 é possível observar um movimento mais acentuado na busca da Marinha brasileira por fornecedores alternativos. Ainda que não houvesse indícios de revisão da doutrina estratégica naval, o Programa Decenal da Marinha de 1967, fundamentava-se, entre outros motivos, sobre as dificuldades impostas pelos EUA à aquisição de equipamentos mais modernos e de peças de reposição (Martins Filho, 2015, p. 78). Após diversas visitas a estaleiros europeus e norte-americanos e revisão de alguns pontos incialmente ensejados pelo Programa, há a decisão pela compra de fragatas junto ao estaleiro inglês Vosper.

Como bem documentado por Martins Filho (2015), o acordo foi festejado pelos parceiros ingleses, que viam no negócio uma oportunidade de ampliar a influência britânica sobre a doutrina e armamentos empregados pela Marinha brasileira - que por muitos anos esteve sob a influência norte-americana. Contudo, a decisão pelas fragatas 
inglesas não partiu de uma revisão da preocupação da Marinha brasileira com a guerra antissubmarina. Voltadas para uso tanto antissubmarino como de emprego geral, apenas duas das seis fragatas adquiridas foram preparadas para emprego geral armadas com mísseis superfície-superfície -, enquanto nenhuma delas recebeu armamento antiaéreo moderno (Martins Filho, 2010a, p. 68).

A década de 1970 ainda foi marcada pelo pensamento da Escola Superior de Guerra (ESG) a respeito do Brasil "Grande Potência", que também influenciava a política externa do país. No entanto, frente às barreiras impostas para a aquisição de armamentos de alto nível tecnológico, e a natureza dos conflitos no plano internacional que restringia a ação estratégica do país, foram evidenciadas algumas limitações e insuficiências analíticas do pensamento da ESG. Uma das consequências dessas limitações foi o crescente questionamento dos princípios esguianos por parte de setores das forças armadas.

Segundo Vitelli (2015, p. 12), ao redor desses elementos, foi se consolidando a premissa de que o Brasil deveria definir seus interesses estratégicos de maneira autônoma. Nesse sentido, um dos setores militares mais críticos às premissas esguianas emergia no âmbito da Marinha, particularmente entre o final da década de 1960 e o começo da década de 1970. Alguns dos militares que participaram das discussões acerca do projeto do submarino de propulsão nuclear protagonizaram os debates críticos ao pensamento da ESG, como os almirantes Mario César Flores e Armando Amorim Ferreira Vidigal (Vitelli, 2015, p. 13).

Ademais, o condicionamento de respeito aos direitos humanos imposto pelo governo Carter para a ajuda militar a países aliados levou o Brasil a denunciar o Acordo Militar e encerrar a Missão Naval Americana, em 1977 (Vidigal, 1985, p. 104). Sob esse contexto, desde fins da década de 1970, o Brasil empenhou esforços no desenvolvimento de um programa tecnologicamente autônomo para a construção de um submarino de propulsão nuclear, que, quando concluído, o elevaria a um patamar restrito de países que possuem um armamento dessa natureza. Do ponto de vista estratégico, a justificativa básica do projeto assentava-se sobre a eficácia do submarino 
em garantir a defesa da plataforma marítima brasileira, dadas suas características de discrição, autonomia e velocidade.

\section{O PROJETO DE DESENVOLVIMENTO DO SUBMARINO NUCLEAR BRASILEIRO}

Já no ano de 1976, o subsecretário de Pesquisa Tecnológica e Científica da República Federal da Alemanha, Hans-Hilger Haunschild, contatou o presidente da Nuclebras, Paulo Nogueira Batista, para destacar o know-how de seu país no desenvolvimento da propulsão nuclear naval (Martins Filho, 2011, p. 279). Posteriormente, a presidência da Nuclebras, por intermédio de seu assessor, realizou tratativas com o subchefe de gabinete do ministro da Marinha, comandante Armando Vidigal, o qual reafirmou o interesse da Marinha no projeto de propulsão nuclear. No mesmo ano, o então diretor-geral do Material da Marinha, almirante Espellet, em visita ao estaleiro da empresa inglesa Vickers-Armstrong, conversou com o presidente dessa

firma a respeito da tecnologia dos submarinos de propulsão nuclear da classe Churchill, construídos naquele estaleiro (Martins Filho, 2011, p. 281).

No retorno ao Brasil, o almirante Espellet teria comunicado o ministro da Marinha, além de contatar o diretor de Engenharia Naval da Marinha Brasileira, Nelson Xavier, a fim de indicar um oficial para que cumprisse o curso de Energia Nuclear do Instituto de Tecnologia de Massachussets (Espellet, 2009 apud Martins Filho, 2011, p. 281). O nome indicado pelo almirante Nelson Xavier foi o do capitão-tenente Othon Luiz Pinheiro da Silva. No entanto, apesar dessas tratativas, cabe pontuar que pelo menos desde 1974 a Marinha brasileira já fazia registro dos avanços tecnológicos relacionados à propulsão nuclear. Como indica o documento da Escola Superior de Guerra (1975) "[...] há dois projetos em estudo destinados a causar grande impacto, a saber: a construção ou aquisição de um porta-helicópteros e a adoção de propulsão nuclear em unidades navais" (Escola Superior de Guerra, 1975, p. 46 apud Martins Filho, 2011, p. 281).

Em seu retorno ao Brasil, em 1978, Othon foi alocado pelo diretor-geral do Material da Marinha, almirante Maximiano da Fonseca, na Diretoria de Engenharia Naval (DEN). Durante seus primeiros meses de atividade na DEN, Othon elaborou um relatório a respeito da possibilidade de desenvolvimento da propulsão nuclear no país. De acordo com Martins Filho (2011, p. 282), o relatório era estruturado em duas metas 
principais para que fosse alcançada a capacidade de desenvolver um submarino à propulsão nuclear: domínio do ciclo do combustível nuclear e construção de um reator piloto para testes. Posteriormente, seu relatório foi encaminhado para o Estado-Maior da Armada (EMA), onde obteve parecer favorável do subchefe de Estratégia do EMA, almirante Flores.

O projeto de desenvolvimento da tecnologia de propulsão nuclear para o submarino estava inserido no escopo do Programa Autônomo de Tecnologia Nuclear (PATN), diretamente vinculado à Presidência da República e supervisionado pelo Conselho de Segurança Nacional (CSN). Em sua execução, o projeto contava com a associação das áreas técnicas das três forças armadas, bem como de órgãos especializados (Brasil, 1985). Os objetivos associados ao PATN estendiam-se desde uso civil até finalidades militares, carregando a expectativa de resultados diversos para a aplicabilidade da tecnologia nuclear. No entanto, a despeito da heterogeneidade de interesses, os atores envolvidos no programa compartilhavam a crença comum de que o programa representaria avanços no sentido da autonomia tecnológica do país (Barletta, 1997, p. 3).

Já no início da década de 1990, a ascensão de Collor à presidência foi marcada por uma diminuição das verbas suplementares do programa do submarino nuclear. Em contrapartida, o almirante Flores foi indicado para o cargo de ministro da Marinha, o que favoreceu a manutenção de recursos para o projeto. Em entrevista concedida a Martins Filho (2011), o ex-ministro afirmou: "tive influência para impedir que o projeto caísse no ostracismo completo. O presidente Collor decididamente não era simpático ao projeto, tinha lá suas razões políticas, de política externa. Nunca se manifestou a mim peremptoriamente contrário, mas nunca se manifestou entusiasmado" (Martins Filho, 2011, p. 310).

Todavia, com o impeachment de Collor no final de 1992, e a posse do vicepresidente Itamar Franco, o almirante Ivan Serpa assumiu o cargo de ministro da Marinha. A postura adotada por Serpa, e que em certa medida também foi promovida pelo ministro da Marinha de Fernando Henrique Cardoso, almirante Mauro, foi mais crítica que a de Flores em relação ao programa do submarino nuclear. Então ministro da 
Marinha no governo de Fernando Henrique Cardoso, Mauro justificou a redução de recursos voltados para o projeto do submarino nuclear sob o argumento do fardo que o projeto representava para o orçamento da força (Martins Filho, 2011, p. 290).

Somente a partir do governo de Lula da Silva foram instauradas as condições para uma nova valorização do projeto de desenvolvimento do submarino nuclear. Ao longo da década de 2000, o setor de Defesa obteve destaque na pauta das políticas públicas do governo brasileiro. No entanto, apenas durante o segundo governo Lula, no início de 2007, e com a escolha do almirante Moura Neto para o comando da Marinha, o submarino nuclear foi recolocado como prioridade da força. Intrínseco a esse processo está a publicação dos documentos estratégicos brasileiros, em especial a Estratégia Nacional de Defesa (END), de $2008^{3}$.

De maneira geral, parte dos objetivos expressos no conjunto dos documentos manifesta uma preocupação com o reaparelhamento das Forças Armadas e o incentivo ao desenvolvimento de capacidades industriais e tecnológicas por parte das empresas que compõem a Base Industrial de Defesa (BID). Assentada sobre o binômio DefesaDesenvolvimento, a perspectiva assumida por esses documentos compreende o conjunto de indústrias de defesa como vetor de inovação e difusão tecnológica para os demais setores industriais ${ }^{4}$.

Nesses termos, a perspectiva do então governo acerca da indissociabilidade entre a estratégia de defesa e a estratégia de desenvolvimento é um importante fator para compreender o interesse político (Saint-Pierre, 2009, p. 22). O vínculo entre tais estratégias está baseado sobre a variável da autonomia tecnológica, que forneceria subsídios para ambas. Dessa forma, a aquisição de capacidades tecnológicas é entendida como subsídio fundamental não apenas para o fortalecimento da autonomia estratégica do país, mas também para garantir a execução de seu próprio modelo de desenvolvimento, conforme demonstra o excerto a seguir:

\footnotetext{
${ }^{3}$ Atualizada em 2012 e 2016.

${ }^{4}$ Além da END, Além da END, outras iniciativas de apoio à indústria de defesa merecem destaque, inclusive aquelas que não guardam correspondência direta com o Ministério da Defesa, destacando-se a Política de Desenvolvimento Produtivo (PDP), de 2008, e o Plano Brasil Maior (PBM), de 2011. Ambas as políticas industriais adotadas durante o governo Lula da Silva e Dilma Rousseff, respectivamente, compreendiam a BID enquanto relevante vetor de inovações tecnológicas para a indústria do país.
} 
estratégia nacional de defesa é inseparável de estratégia nacional de desenvolvimento. Esta motiva aquela. Aquela fornece escudo para esta. Cada uma reforça as razões da outra. Em ambas, se desperta para a nacionalidade e constrói-se a Nação. Defendido, o Brasil terá como dizer não, quando tiver que dizer não. Terá capacidade para construir seu próprio modelo de desenvolvimento [...] Não é independente quem não tem o domínio das tecnologias sensíveis, tanto para a defesa, como para o desenvolvimento (Brasil, 2012, p. 43-44).

Para tanto, o documento aponta que seriam buscadas parcerias com outros países, com o propósito de desenvolver a capacitação tecnológica e a fabricação de produtos de defesa nacionais, de modo a eliminar, progressivamente, a dependência de serviços e produtos importados (Brasil, 2012). Como destaca Vitelli (2015, p. 31), a natureza dual de alguns projetos estratégicos das forças armadas também fundamenta o argumento sobre a indissociabilidade das estratégias de defesa e desenvolvimento.

À luz dessas considerações, os documentos indicam que o país necessita de um instrumento militar moderno se pretende exercer um papel protagonístico no sistema internacional, de modo que transmita o compromisso e a capacidade necessários para exercer tal papel (Vitelli, 2015, p. 31). Em relação à Marinha brasileira, é apresentada a hierarquia dos objetivos estratégicos e táticos da força, os quais compreendem a negação do uso do mar, a projeção de poder, e o controle de áreas marítimas.

A negação do uso do mar a qualquer força inimiga, e seu esforço subsidiário de assegurar os meios necessários para tanto, é o que organiza a estratégia marítima do Brasil (Brasil, 2012, p. 67). Sob esse escopo, o objetivo de projeção de poder mantém-se hierarquicamente subordinado à negação do uso do mar. Como é destacado no documento, tal prioridade de objetivos carrega implicações para a reconfiguração da força naval. Para assegurar seu objetivo prioritário, a Marinha indica o papel central a ser exercido por uma força naval submarina - composta por submarinos convencionais e de propulsão nuclear (Brasil, 2012, p. 71). A esse respeito, o almirante Vidigal argumenta que

a Marinha brasileira, como, aliás, todas as Marinhas do mundo, via no submarino nuclear a solução para o seu problema estratégico, uma espécie de ruptura tecnológica que a levaria ao nível das melhores marinhas e a colocaria em posição de grande superioridade diante de marinhas que não pudessem dispor dessa arma. (Vidigal, 2002, p. 13 apud Martins Filho, 2010a, p. 70). 
Sob esse contexto, foi firmado, em 2008, o acordo de cooperação tecnológica entre Brasil e França, que deu as bases para o Programa de Desenvolvimento de Submarinos (PROSUB). Este acordo tem como objetivo a construção de quatro submarinos convencionais e a transferência de tecnologia sobre a parte não nuclear do submarino nuclear, além da construção do complexo de Estaleiro e Base Naval (EBN) e da Unidade de Fabricação de Estruturas Metálicas (UFEM) - esta última inaugurada no início de 2013. Em dezembro de 2018 foi lançado ao mar o primeiro submarino convencional do Programa - S-BR Riachuelo; e no final de 2019 foi realizada a união das sessões do segundo submarino convencional - S-BR Humaitá -, com previsão de lançamento ao mar em 2020.

Entretanto, a despeito desses avanços, o Programa tem apresentado recorrentes mudanças no cronograma em função de restrições orçamentárias impostas, pelo menos, desde 2015 (Ministério da Defesa, 2015). Inicialmente previsto para 2022, a previsão de entrega do submarino de propulsão nuclear é 2032. A esse respeito, cabe pontuar que o contrato de financiamento internacional do Programa tem vigência até 2025, e, caso a execução dos contratos comerciais exceda esse prazo, será necessário renegociar a extensão do período de financiamento (Poder Naval, 2020).

Frente ao volume de investimentos necessários para a consecução de um Programa dessa extensão, as recentes dificuldades orçamentárias da Marinha brasileira lançam luz sobre um problema recorrente aos países situados na periferia internacional. Como discutido anteriormente, o nível de intensidade tecnológica incorporado aos modernos sistemas de armas torna cada vez mais onerosos esforços de modernização militar. Refletindo a esse respeito, o almirante Vidigal pontuou suas preocupações em relação aos custos do programa para a Marinha:

Nosso objetivo supremo é o submarino nuclear. E eu tenho medo de que isso não seja saudável para a Marinha. Do mesmo modo de que no passado nós nos fixamos na guerra antissubmarino, como a solução de todos os problemas navais, e deixamos de enxergar outras coisas que podiam estar acontecendo, eu tenho medo de que o submarino nuclear possa ter esse mesmo papel no futuro [...] Eu digo com muito receio porque a Marinha transformou o submarino nuclear em um símbolo, e quem for contra esse símbolo vai encontrar uma séria oposição na Marinha. (Vidigal, 2009 apud Martins Filho, 2011, p. 294-295, grifo nosso). 
Coerente com essa leitura, o então coordenador da Coordenadoria Geral do Programa de Desenvolvimento do Submarino Nuclear (COGESN), almirante José Alberto Fragelli, argumentou que o submarino nuclear não só auxiliaria o país a conquistar um assento permanente no Conselho de Segurança da ONU, como também tornaria o Brasil "muito maior do que é hoje como nação, do ponto de vista militar e estratégico" (Fragelli, 2009).

Nesses termos, para além deu suas potencialidades operacionais para a capacidade dissuasória da Marinha, o submarino de propulsão nuclear também cumpre o papel simbólico de integrar o país e sua força naval ao que é compreendido enquanto poder militar moderno. Produto de um processo de isomorfismo institucional moldado ao longo da história, a demanda pelo submarino de propulsão nuclear, para além de atender aos anseios "modernos" da organização militar, também é instrumento do esforço brasileiro de reconhecimento e inserção internacional.

\section{CONSIDERAÇÕES FINAIS}

A partir do exposto nas seções anteriores, entendemos que o desenvolvimento que levou à demanda da Marinha brasileira pelo submarino de propulsão nuclear mostra-se coerente com o processo de isomorfismo institucional apontado pelo neoinstitucionalismo sociológico. Três períodos distintos no desenvolvimento histórico da Marinha brasileira coincidiram com a incorporação de novos armamentos, que, além de representarem saltos tecnológicos, influenciaram o desenho estratégico e o treinamento da força.

A Marinha brasileira sempre buscou inspiração na Marinha inglesa, que, durante meados do século XIX e início do século XX, representou a mais poderosa e eficiente força naval. Sob esse quadro, ainda durante o período de formação da Marinha brasileira, a vinda de oficiais e marujos ingleses influenciou os contornos doutrinários da força naval brasileira. Entretanto, após a aquisição dos modernos dreadnoughts, a Marinha brasileira buscou qualificar seu pessoal a fim assegurar o emprego adequado e a manutenção dos novos navios.

Sob esse contexto, a inspiração britânica cede lugar à influência estadunidense na doutrina e nos armamentos da força naval brasileira. Esse período, que se estende até 
1977, é marcado pela crescente dependência e subordinação da força naval brasileira à Marinha estadunidense. O cerceamento imposto pelos EUA no acesso a melhores equipamentos fomentou no seio da Marinha brasileira o entendimento de que o país deveria abandonar o papel auxiliar na defesa do Atlântico Sul.

Esses desenvolvimentos fundamentaram a mudança de visão estratégica na força. Inicialmente, ainda que não fosse proposta uma revisão da concepção estratégica antissubmarina, a aquisição das fragatas inglesas representou um processo de distanciamento da influência estadunidense em favor de parceiros alternativos. Em consonância com esse movimento, a Marinha formalizou uma nova concepção estratégica. Sob esse contexto, e a exemplo das grandes potências, surge o projeto para o desenvolvimento de um submarino de propulsão nuclear. Entendemos que o submarino, para além de seu potencial benefício estratégico, representa um símbolo nos esforços brasileiros de reconhecimento e inserção internacional.

No entanto, cabe problematizar os alcances explicativos da perspectiva do neoinstitucionalismo sociológico. Ainda que a abordagem lance luz sobre um importante fenômeno em nível internacional, uma perspectiva dessa natureza mostrase insuficiente para discutir as disputas internas às organizações militares. Pela análise do processo de desenvolvimento do projeto do submarino de propulsão nuclear, evidencia-se que tal projeto não era unanimidade no âmbito da Marinha. Particularmente durante a década de 1990, nota-se que sua plena manutenção - e fortalecimento - também dependeu da disposição dos ministros da Marinha - bem como da disponibilidade orçamentária - em dispender recursos financeiros para o projeto.

Por fim, ao contrário do que sugerem as leituras tradicionais sobre os sistemas de armas - que tendem a enfocar as qualidades técnicas que exercem efeitos sobre a eficiência e a eficácia do empreendimento da violência -, estes não apenas incidem sobre elementos de ordem econômica, social e política, mas também são afetados e constituídos por esses meios. Nesses termos, a tecnologia militar não pode ser reduzida às suas funções instrumentais, isto é, enquanto produto da técnica e objeto sujeito ao constante progresso tecnológico. Os sistemas de armas não pairam como um elemento 
exógeno, mas como um nó elementar na teia de interações que articulam as questões de defesa, segurança e as relações internacionais de um modo amplo.

\section{REFERÊNCIAS BIBLIOGRÁFICAS}

Alves, V. (2005). 'Ilusão desfeita: a "aliança especial" Brasil-Estados Unidos e o poder naval brasileiro durante e após a Segunda Guerra Mundial', Revista Brasileira de Política Internacional, 48(1), pp. 151-177.

Arias Neto, J. (2014). 'A Marinha brasileira no início do século XX: tecnologia e política', Antíteses, 7(13), pp. 84-112.

Barletta, M. (1997). The military nuclear program in Brazil. Center for International Security and Arms Control. California.

Battaglino, J. (2008). 'Palabras mortales: rearme y carrera armamentista en América del Sur?', Nueva Sociedad, n. 215, pp. 23-34.

Brasil. (1985). Conselho de Segurança Nacional. Exposição de motivos no 011/85. . (2012). Ministério da Defesa. Estratégia Nacional de Defesa. Brasília.

Brigagão, C. (1984). O mercado da segurança: ensaios sobre economia política de defesa. Rio de Janeiro: Nova Fronteira.

Bromley, M.; Guevara, I. (2010). "Arms modernization in Latin America", in: Tan, Andrew (Org.). The Global Arms Trade: A Handbook. London: Routledge.

Dimaggio, P.; Powell, W. (1983). 'The Iron Cage Revisited: Institutional Isomorphism and Collective Rationality in Organizational Fields', American Sociological Review, 48(2), pp. 147-160.

Eyre, D.; Suchman, M. (1996). "Status, Norms, and the Proliferation of Conventional Weapons: An Institutional Theory Approach", in: Katzenstein, P. J. (org.). The Culture of National Security: Norms and Identity in World Politics. Nova York: Columbia University Press.

Farrell, T. (2005). The Norms of War: Cultural Beliefs and Modern Conflict [VitalSource Bookshelf version]. London: Lynne Rienner Publishers.

Fragelli, J. (2009). "Brasil será muito maior do que é hoje como nação". O Estado de S. Paulo, 16 maio. Disponível em: < https://politica.estadao.com.br/noticias/geral,brasilsera-muito-maior-do-que-e-hoje-como-nacao,372148> [Acesso em: 15 jan. 2020].

Goldman, E. (2002). "The Spread of Western Military Models to Ottoman Turkey and Meiji Japan", in: Farrell, T.; Terriff, T. (Org.). The sources of military change: culture, politics, technology. London: Lynne Rienner Publishers. 
Kinsella, D. (2013). "The global arms trade and the diffusion of militarism", in: Stavrianakis, A.; Selby, J. Militarism and International Relations: Political economy, security, theory. London and New York: Routledge.

Malamud, C.; Encina, C. (2006). '¿Rearme o renovación del equipamiento militar en América Latina?', Documento de Trabajo, n. 31.

Martins Filho, J. (2015). 'Relações navais entre Brasil e Reino Unido durante a Guerra Fria: o caso da aquisição das fragatas Vosper', Austral: Revista Brasileira de Estratégia e Relações Internacionais, 4(7), pp. 73-103.

$\frac{}{33(2) .}$. (2011). 'O Projeto do Submarino Nuclear Brasileiro', Contexto Internacional, (2010b). A Marinha brasileira na era dos encouraçados, 1895-1910: tecnologia, forças armadas e política. Rio de Janeiro: Editora FGV.

. (2010a). "Marinha: tecnologia e política", in: Domingos Neto, M. (Org.). O militar e a ciência no Brasil. Rio de Janeiro: Gramma.

Ministério da Defesa. (2015). Nota à Imprensa: Contingenciamento 2015. Disponível em: <https://www.defesa.gov.br/noticias/15811-nota-a-imprensa-contingenciamento2015-ministerio-da-defesa/> [Acesso em: 10 jan. 2020].

Poder Naval. (2020). Programas da MB em 2019: PROSUB. 2020. Disponível em: <https://www.naval.com.br/blog/2020/01/12/programas-da-mb-em-2019-prosub/>. [Acesso em: 15 jan. 2020].

Sagan, S. (1996). 'Why Do States Build Nuclear Weapons?: Three Models in Search of a Bomb', International Security, 21(3).

Saint-Pierre, H. (2009). 'La Defensa en la Política Exterior del Brasil: el Consejo Suramericano y la Estrategia Nacional de Defensa', Análisis del Real Instituto Elcano, v. DT, p. 50.

SIPRI, Arms Transfers Database. (2019). Disponível em: <https://www.sipri.org/databases/armstransfers>. [Acesso em: 20 jan. 2019].

Svartman, E. (2011). 'Brazil-United States military relations during the Cold War: political dynamic and arms transfers', Brazilian Political Science Review, v. 5.

Villa, R. (2008). 'Corrida armamentista ou modernização de armamentos na América do Sul: estudo comparativo dos gastos militares', Estudos e Cenários, pp. 1-54.

; Weiffen, B. (2014). 'South American Re-armament: From Balancing to Symbolizing Power', Contemporary Security Policy, 35(1), p. 138-162.

Vitelli, M. (2015). 'Argentina, Brasil y la defensa en América del Sur: las identidades estratégicas y la seguridad regional', Cuadernos política exterior argentina. 
Wendt, A; Barnett, M. (1993). 'Dependent state formation and Third World militarization', Review of International Studies, v. 19. 